\title{
Reproductive health care is marginalized
}

\author{
Primary care physicians are in a unique position to lobby for services
}

Soon after I arrived in Washington, DC, people asked me-a British woman-what the law in my country was on abortion. I explained that if you wanted to terminate a pregnancy, you went to your primary care physician or to the local family planning clinic, where everything would be arranged. The National Health Service pays for this procedure. There are no placard-carrying antiabortionists outside the clinics getting in your way. Abortion is not a major issue in Britain - it is just a necessary, albeit unfortunate, part of life. I never thought that it had anything to do with politics.

In the United States, I was shocked to find that all aspects of reproductive health are seen as political — even sex education and contraception. In 1997, Congress, which was cutting public spending, voted to spend $\$ 250$ million on abstinence-only sex education. Everyone in the country has an opinion on abortion.

The result of the personal being made political is that, despite US law supporting a woman's right to make reproductive choices, a woman who chooses to terminate a pregnancy may find it extremely difficult to do so. In $86 \%$ of US counties, there is no physician to provide abortions. ${ }^{1}$ Only $14 \%$ of US hospitals permit abortions to be performed at the facility, and many of these are done only in very limited circumstances. ${ }^{1}$ One in 10 women has to travel more than 100 miles to find an abortion provider. ${ }^{2}$ In 31 states, young women must have parental permission or notify their parents before having an abortion, and 14 states have statutory waiting periods. ${ }^{3}$ Medicare and Medicaid do not cover abortions, except in cases of rape, incest, or if the life of the woman is in danger. Military women serving overseas cannot have an abortion in an American hospital, even if they pay for it themselves. ${ }^{4}$ The list of barriers to women wanting basic health care continues to grow.

As the political and legal debate continues, the lives of real women are affected. During the 4 years I worked for Choice USA, a prochoice education and activist organization, I met many such women. Their histories are now in the public domain. There are the 15-year-old best friends who were gang raped, and both became pregnant. One was able to talk to her parents - a legal requirement before an abortion can be obtained-and the termination went ahead. Her friend shot herself dead because she was too scared to tell her parents about the pregnancy. Then there is the woman in Texas on the heart transplant list who was refused an abortion in her hospital. The hospital offers a termination only if the risk of dying due to con- tinuing a pregnancy is higher than $50 \%$. Her risk was just under $50 \%$. I also remember a young woman who ended up having an abortion well into the second trimester because it took her months to negotiate all the barriers that were placed in her way.

What can be done to reverse this marginalization of women's reproductive health rights? Medical professionals are in a unique position to contribute in ways that others cannot.

First, they can publicly support colleagues who provide abortions. There are so few abortion providers partly because elements in the antichoice movement have harassed, bullied, injured, and killed health professionals because of the job they do. Abortion services have consequently been sidelined, making them even easier targets. Medical professionals can address this by publicly supporting abortion providers and advocating for the provision of abortion in hospitals. If every primary care physician had information on the whole range of pregnancy options (including abortion), if every hospital provided abortions, and if every medical student was taught how to perform an abortion, then the target would be too big for the antichoice movement to attack. Antichoice activists and terrorists cannot bomb every hospital, cannot blockade every clinic, and cannot harass every physician and medical student.

Second, medical students, trainee midwives, and clinicians can choose to learn how to perform an abortion if it is offered as part of their training. If they are not offered this, they can campaign to have abortion training pro-

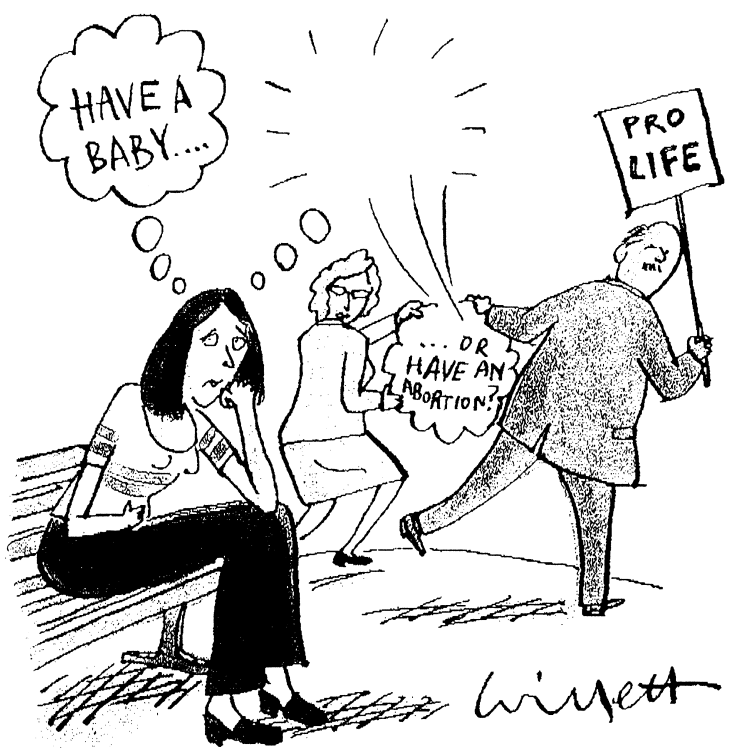

Kate McCarthy

Labour Party Millbank Tower Millbank

London SW1P 4GT

Correspondence to: Ms McCarthy Katemccarthy@attglobal. net

Competing interests: $\mathrm{Ms}$ McCarthy worked for Choice USA between 1996 and 2000. She is now employed by the Labour Party as its E-Campaign Manager.

West J Med 2000;173:151-152 
vided. At present, only $12 \%$ of obstetrics-gynecology programs require abortion to be learned, $56 \%$ have it as an option, and $26 \%$ do not even have it as an option. ${ }^{5}$ When abortion is twice as common an operation as tonsillectomy in the United States, it is frightening to think that physicians are not trained how to perform them. ${ }^{6,7}$

Third, primary care physicians can display literature in their clinics highlighting the whole range of reproductive health care options - including abortion and adoption. They can build links with local family planning organizations and abortion providers and can make condoms freely available to their patients.

Fourth, physicians can support prochoice students. Medical professionals are ideally qualified to give advice to pregnant students who want to know their options and to participate in education and training activities.

Finally, they can vote prochoice. The general election in November is of particular importance because it is likely that the next president will appoint several new Supreme Court justices. There are currently 5 prochoice and 4 antichoice justices. The reproductive choices of American women will be severely limited if an antichoice president appoints antichoice judges to the Supreme Court.

I returned to Britain more aware of the problems with the British legal position on abortion and of the geographic variations in service provision-it is far from perfect in the United Kingdom-but even more thankful that the British public support women having choices. I am continually heartened that the debate has remained out of the political arena. We have had only 1 vote in our parliament on abortion since 1967, when abortion was made legal, compared with the 239 votes in Congress since Roe $v$ Wade in $1973 .^{8}$
What scares me coming back to the UK is the evangelic antichoice US organizations that have begun to spring up in Britain and the tactics of violence and intimidation that they are using to try to close our clinics and scare our professionals. There will be a massive grassroots response to their tactics of hate. This response will ensure that unnecessary and complicated barriers are not erected to prevent pregnant women having access to all the options and all the medical services they need. Abortion is a mainstream medical service. We will not let Britain go the way of the United States and have reproductive health care marginalized.

Medical professionals who wish to become involved in the prochoice movement can contact the National Abortion Federation ([202] 667-5881). Medical students can contact Medical Students For Choice ([510] 540-1195).

References

1 Henshaw SK. Abortion incidence and services in the United States, 1995-1996, Fam Plann Perspect 1998;30:263-270, 287.

2 Henshaw SK. Factors hindering access to abortion services, Fam Plann Perspect 1995;27:54-59, 87.

3 The status of major abortion-related laws and policies in the states. Alan Guttmacher Institute; 2000

4 The status of major abortion-related policies in the states. Alan Guttmacher Institute; 1999.

5 MacKay HT, MacKay AP. Abortion training in obstetrics and gynecology residency programs in the United States, 1991-1992. Fam Plann Perspect 1995;27:112-115.

6 Centers for Disease Control and Prevention (CDC). Ambulatory and inpatient procedures in the US, 1996. Nov 1998.

7 USPHS-CDC News. Abortion surveillance: preliminary analysis-US, 1997. Ann Pharmacother 2000;34:556.

8 Choice USA Congressional Database.

\section{Medicine in the 1800 s}

The truth is that medicine, professedly founded on observation, is as sensitive to outside influences, political, religious, philosophical, imaginative, as is the barometer to the changes of atmospheric density. Theoretically it ought to go on its own straightforward inductive path, without regard to changes of government or to fluctuations of public opinion. [But, there is] a closer relation between the Medical Sciences and the conditions of Society and the general thought of the time, than would at first be suspected.

Oliver Wendall Holmes

Currents and Counter-currents in Medical Science, 1860

How can a man spend his whole life in seeing suffering bravely borne and yet remain a hard or a vicious man? It is a noble, generous, kindly profession, and you youngsters have got to see that it remains so.

Arthur Conan Doyle

The Surgeon Talks, 1894 